\title{
Field Dependence/Independence, Impulsivity/Reflectivity, Gender, and Cloze Test Performance of Iranian EFL Learners: A Study of Relations
}

\author{
Mina Rastegar, Associate Prof. in TEFL \\ NazaninMehrabizadehHonarmand, M.A. TEFL \\ Department of English Language and Literature \\ ShahidBahonar University of Kerman
}

doi: 10.19044/esj.2016.v12n8p408 URL:http://dx.doi.org/10.19044/esj.2016.v12n8p408

\begin{abstract}
This study aimed at exploring any significant relationships among field dependence/independence, impulsivity/reflectivity, and cloze test performance of Iranian EFL learners, and attempted to seek any significant differences between males and females regarding their field dependence/independence, impulsivity/reflectivity, and cloze test performance. Participants were 72 (47 females and 25 males) Iranian EFL university students in ShahidBahonar University of Kerman. Group Embedded Figures Test (GEFT) by Witkin et al. (1971), Impulsivity subscale of Impulsiveness, Venturesomeness, and Empathy (IVE) scale by Eysenck and Eysenck(1978), and a cloze test consisting of two cloze passages (Oller\& Perkins, 1980) were utilized to obtain the required data.To statistically analyzethe data, the statistical procedures of Pearson Product Moment Correlation and Independent Samples T-test were utilized using SPSS version 21. The findings of this study indicated that field independence had a significant positive correlation with reflectivity, and field dependence also had a significant positive correlation with impulsivity. However, the findings revealed no significant relationship between cloze test performance and any of other variables. It was also found that females are more reflective and males tend to be more impulsive.
\end{abstract}

Keywords: Cognitive style, Field dependence, Field independence, Impulsivity, Reflectivity, Gender, EFL students, Cloze test 


\section{Introduction}

Students have different abilities in learning a foreign or second language.

To be more specific, they use different learning strategies and learning styles. Among different factors that may affect foreign language learning, field dependence/independence as a cognitive style has attracted much attention. Some researchers have studied the relationship between field dependence/independence and different language skills. On the other hand, impulsivity/reflectivity as another cognitive style isan important factor which has to be considered. Some studies reveal interesting points about field dependent/independent and impulsive/reflective students and different routes and rates they have in mastering a foreign or second language.

Cognitive style is defined as the way a person learns materials or finds solutions to the problems (Brown, 2007). In a field dependent mode of discerning, organization of the field dominates recognition of its parts; individual items within a field merge into their background. In contrast, in a field independent mode of discerning, the individual is able to discern items as discrete from the organized field of which they are a part (Witkin, 1967). Reflection/impulsivity refers to "the tendency to reflect over alternative solutions or classifications in which several response alternatives are available simultaneously" (Kagan, Rosman, Day, Albert, \& Phillips, 1964, p. 2).

The term cloze was first used by Taylor in 1953. A cloze test is a technique for measuring reading comprehension as well as overall language proficiency. In a cloze test, words are deleted from a reading passage at regular intervals, leaving blanks. The ability to fill in the blanks within a passage indicates the comprehension ability of reader (Farhady, Jafarpur, \&Birjandi, 2012).

The present study investigated the relationships among field dependence/independence, impulsivity/reflectivity, and gender, considering second language test performance, especially as it relates to performance on an integrative type of measure known as cloze test.

\section{Literature Review}

\section{Field Dependence/Independence}

Field dependence and field independence were developed by Witkinto represent the contrasting differences between field dependent (global) and field independent (analytic) cognitive styles. Field dependence/independence style determines the way individuals experience their surroundings, either globally or analytically. People who are field dependent have a general view of things, failing to focus on minor details. On the contrary, field independent people are keen observers with an eye for 
details, ignoring the background in which the details emerge. Field dependent individuals rely on external signals and shapes, have short memory spans, are simply distracted and prefer natural learning situations. On the contrary, field independent individuals are naturally more motivated, more investigative and self-reliant, have higher concentration and longer memory spans, rely more on internal signals and prefer academic environments in which they can achieve their goals through competition (Blakely \& Tomlin, 2008).

Brown (2007) considered both styles as important,and observed that they deal with two different kinds of language learning. Field independence is related to classroom learning and includes analyzing, considering details, learning drills, exercises, and tests, while field dependence is related to nonacademic language learning mainly in communicative aspects and scarcely in the average language classroom.

Rozencwajgand Corroyer (2005) studied the relationship between field dependence/independence and impulsivity/reflectivity. Theymentioned that field dependent individuals and impulsive individuals both use a holistic, global processing mode and field independent individuals and reflective individuals both use an analytic processing mode, thereforeit would be difficult to differentiate the two cognitive styles.

Campbell and Douglas (1972) investigated field dependence/independence and impulsivity/reflectivity among children. They reported that more reflective children are field independent, and impulsive children are filed dependent.In one study of males with serious behavioral and learning disorders conducted by Keogh and Donlon (1972), the results came out that males with learning disorders were field dependent, and males with extreme learning disorders were both field dependent and impulsive.

Massari (1975) reported that reflective children are more filed independent.In another study, Feij (1976) found that field independent students were reflective. However, he pointed out that field dependence and impulsivity were unrelated measures. He also reported a negative correlation between impulsivity and statistics grades, and concluded that cognitive styles have probably relevance in predicting academic evolution.

Loo and Townsend(1977) found that field independence was associated with low impulsivity and slow decision making which implies reflectivity. Gargiulo (1982) conducted a research among children, measuring their levels of field dependency/independency and impulsivity/reflectivity. He concluded that mentally retarded children were significantly filed dependent and impulsive. Gargiulo (1982) also found a significant positive relationship between field independency and reflectivity. In another study, Rozencwajg and Corroyer (2005) found that fast-accurate individuals achievedthe highest scoreson the GEFT, and reflective 
individuals (slow-accurate) achieved higher scores than impulsive learners (fast-inaccurate).

However, some other researchers reported differently.Messer (1976) reported a moderate non-significant relationship between these learning styles, and pointed out that this might be due to the similarity of the conducted tests.Jamieson (1992) reported some degree of overlap in these two cognitive styles, but no strong or significant relationship between field independence and impulsivity/reflectivity was found. Lotwick, Simon, and Ward (1981) investigated the relationship between polytechnic students' gender and their cognitive styles. They reported a significant relationship between field dependence/independence and gender, indicating greater field dependence among females than males.In another study similar results were obtained by Bosacki, Innerd, and Towson (1997). However, Morf, and Howitt (1970) and Khan (1987) discovered no gender differences among males and females regarding their field dependency/ independency. Rezai and Noori (2013) mentioned that gender hadan effect, not on field independency, butjust on field dependency indicating that males were more field dependent than females. In a recent study, Onyekuru(2015) studied secondary school students in Nigeria. He found that a higher proportion of males were field independent while a higher proportion of the females were field dependent.

Most researchers hadfound that a tendency towards field independency helpedstudents with conventional classroom learning.Hansen and Stansfield (1981) indicated that fieldindependency played a major role in second language acquisition, especially in linguistic competence and integrative competence and hardly perceptible in the acquisition of communicative competence. In the same study they found a positive relationship between field independency and satisfactory scores on cloze tests.

According to Jamieson (1992) who found a positive relationship between field independence and language proficiency, field independence was positively correlated with success on the Test of English as a Foreign Language(TOEFL). However, field independency could not anticipate a student's success throughout the semester.

Blanton (2004) conducted different models of reading comprehension test to compare the means of scores with students' cognitive styles. She found thatthe format of the test items had a significant effect on fielddependent students' performance: The studentsperformed significantly better in the un-timed multiple-choice test than the timed one. Field independent students performed better than field dependent students in both timed and un-timed multiple choice tests. She also concluded thatcognitive style had 
more effect than ethnicity or gender on students' performance on a standardized test of reading comprehension.

Maghsudi (2007) also examined the relationship between field dependence/independence and English achievement test performance. The results revealed that field independent learners exceled in classroom learning, which involved analysis, attention to details, and mastering of exercises, drills and other focused activities. Rezai and Noori (2013) reported that less proficient students were more field dependent. They also concluded that as the students' level of filed dependency decreased as they became more proficient, but field independency did not seem to be under the influence of proficiency level.

However, few studies reported different results.Wells (2000) found no significant difference between the two cognitive styles regarding course achievement among learners who had enrolled in a graduate online education course.In a similar study, Shih and Gamon (2001) studied field dependence and field independence among students who had registered for an online biology or zoology course. They reported no significant difference between field dependent and field independent students concerning their course achievement. Soozandehfar and Souzandehfar (2011) reported a nonsignificant relationship between the GEFT scores and speaking performance.

\section{Impulsivity/Reflectivity}

Kagan et al. (1964) were the first researchers to propose the term impulsivity/reflectivity, which they measured using the Matching Familiar Figures Test (MFFT). Reflectivityand also the ability to distinguish relevant from irrelevantfacets of a promptcontribute mainly to the analysis of a concept. According to Brown (2007), impulsivity is defined as the inclination to resolve problems hastily, making chance decisions or high-risk decisions. Reflectivity or reflective style is the tendency tospend a comparably long time for making a decision or finding an answer to a problem, sometimes to consider all possibilities before making a decision.

Lewis, Rausch, Goldberg, and Dodd (1968) concluded that boys were more impulsive than girls, and that their errors significantly correlated with their response speed. In a similar study by Lewis (1971) the same results were obtained. However, Messer (1976) found no gender difference on the basis of impulsivity/ reflectivity.

Jamieson (1992) reported that impulsivity and reflectivity were neither positively nor negatively related to language proficiency. Considering reflective students slow and accurate and impulsive ones fast and inaccurate, Jamieson adds that these dimensions might cancel each other on a timed test; reflective students answer fewer questions but get more right out of them, while impulsive ones answer more questions but also make 
more errors. She concluded that fast accurate learners performed better in language proficiency tests.Bazargani and Noroozi (2013) found thatreflective participants performed better than the impulsive ones on the multiple choice items.

\section{Cloze Test Performance}

As it was mentioned earlier, most researchers concluded that a tendency towards field independency helped students with conventional classroom learning. Chapelle and Roberts (1986) found a significant correlation between field independence andcloze test performance in ESL students. In a similar study, Hansen and Stansfield (1981) found a positive relationship between field independence and scores on L2 tests, particularly in the case of the cloze tests.

In the case of gender differences, according to Hansen and Stansfield (1981) a positive and significant correlation was found between students' gender and their language proficiency; females consistently performed at a higher level than males.In another study by Ryan and Bachman (1992), no significant relationship was found between gender and performance on TOEFLand the First Certificate of English (FCE).

Blanton (2004) conducted untimed and timed multiple choice items. Result analysis indicated that there were no significant mean differences between the scores of females and males on all of the formats of the reading tests. She found that cognitive style had more impact on students' performance on reading comprehension than did ethnicity or gender. Bazargani and Noroozi (2013) investigated gender and performance on multiple choice items. They found that learners' gender did not affect their performance on multiple-choice tests.

\section{Research Questions}

The present study investigated the relationships among the cognitive styles of field dependence/independence and impulsivity/reflectivity, gender, and cloze test performance of EFL university students. Therefore, the following research questions were formed:

1. Is there a significant relationship between field dependence/independence and cloze test performance?

2. Is there a significant relationship between impulsivity/reflectivity and cloze test performance?

3. Is there a significant relationship between field dependence/independence and impulsivity/reflectivity?

4. Are there any differences between males and females regarding their scores on field dependence/independence, impulsivity/reflectivity, and cloze test? 


\section{Methodology \\ Participants}

The participants in this study were 72undergraduate EFL students randomly chosen among EFL students in ShahidBahonar University of Kerman. 47 female students and 25 male students were studied in this case; the distribution percentage of the participants' gender was 65.3 and 34.7 for females and males, respectively.

\section{Instruments}

The following three instruments were used for data collection in this study.

1. The Group Embedded Figures Test (Witkin, et.al., 1971)

2. The Impulsiveness subscale of Eysenck's Impulsiveness, Venturesomeness, and Empathy (IVE) Scale(Eysenck \& Eysenck, 1978)

3. A cloze Test (Oller\& Perkins, 1980)

\section{Group Embedded Figures Test (GEFT)}

The GEFT was developed by Witkin, Oltman, Raskin, and Karp (1971) and it is still the most widely accepted test of measurement for the cognitive styles of field independence and field dependence.Some recent studies which used the GEFT are the studies ofRozencwajg and Corroyer (2005), Maghsudi (2007), Soozandefarand Souzandehfar (2011), and Onyekuru (2015).The GEFT isa group administered test that requires the subjects to identify a simple geometric shape within a complex figure. It includes three sections of increasingly complex geometric figures. The firstsection, which is for practice and is not scored, contains seven figures. The second and third sections each contain nine figures. Students were asked totrace specified simple figures that were embedded in complex designs within a time limit of five minutes for each section. The total test score was the number of simple forms correctly traced in thesecond and third sections, ranging from 0 to 18 . The higher astudent's score is, the more field independent she/he would be. Those whose scores on GEFT are more than mean (10 and more) are classified as field independent and those whose scores are equal to or less than mean ( 9 and less) are field dependent (Blanton, 2004).

\section{The Impulsiveness subscale of Eysenck's Impulsiveness, Venturesomeness, and Empathy (IVE) Scale}

The Impulsiveness subscale of Eysenck's Impulsiveness, Venturesomeness, andEmpathy (IVE) Scale was used to measure the participant's level of impulsivity (Eysenck \& Eysenck, 1978). This questionnaire has 19 items in which the respondents were required to 
indicate with either a "yes" or "no" response, whether they agreed or disagreed with the statement. Items 5, 16, and 17 were reversely scored. Scores range can vary from 0 to 19 with higher scores demonstrating greater levels of impulsivity. Subjects with score equal to 9 and less are considered reflective and those who scored 10 and more are impulsive (refer to its manual).

\section{Cloze test}

Finally, to test the performance of theparticipants on cloze test, two cloze passages (Oller\& Perkins, 1980)were administered to them. One passage contained fifteen and the other had tenitems. Participants had the total time of twenty five minutesfor the two cloze tests. Participants were asked to choose the exact word or words which were deleted; this is called the exact word method.

\section{Data Collection Procedures}

During the data collection phase, one of the researchers was present and administered all tests under standard conditions; the GEFT and the cloze tests had time limits and the participants were not allowed to talk during the test administration.The three questionnaires were attached together and distributed among the participants as one set, so that each participant's score could be matched later on. Participants were reassured that the given information would remain confidential and be employed only for research purposes.The data collected through the GEFT, the IVE subscale, and the cloze tests were imported into SPSS software to determine whether any significant relationships existed among the variables.

\section{Results}

Tables 1 to 5 show descriptive statistics of this study. Table 1 includes the number of participants, range, min, max, mean, standard deviation, and variance of the gathered data.

Table 1. Descriptive Statistics of the Variables

\begin{tabular}{|l|l|l|l|l|l|l|l|}
\hline & $\mathrm{N}$ & Range & Min & Max & Mean & SD & Variance \\
\hline $\begin{array}{l}\text { Field } \\
\text { dependence/independence }\end{array}$ & 72 & 16.00 & 2.00 & 18.00 & 9.37 & 4.57 & 20.97 \\
Impulsivity/Reflectivity & 72 & 13.00 & 2.00 & 15.00 & 7.69 & 3.33 & 11.11 \\
Cloze Test & 72 & 22.00 & 2.00 & 24.00 & 13.29 & 4.48 & 20.12 \\
Valid N (list wise) & 72 & & & & & & \\
\hline
\end{tabular}


Table 2 shows the number of male and female participants.

Table 2. Descriptive Statistics-Gender

\begin{tabular}{|c|c|c|c|c|c|}
\hline & & Frequency & Percent & Valid Percent & $\begin{array}{c}\text { Cumulative } \\
\text { Percent }\end{array}$ \\
\hline \multirow[t]{3}{*}{ Valid } & Male & 25 & 34.7 & 34.7 & 34.7 \\
\hline & Female & 47 & 65.3 & 65.3 & 100.0 \\
\hline & Total & 72 & 100.0 & 100.0 & \\
\hline
\end{tabular}

Table 3 displays the number of participants belonging to field dependent and field independent groups.

Table 3. Descriptive Statistics-Field Dependency Level

\begin{tabular}{|c|c|c|c|c|c|}
\hline & & Frequency & Percent & Valid Percent & $\begin{array}{c}\text { Cumulative } \\
\text { Percent }\end{array}$ \\
\hline \multirow[t]{3}{*}{ Valid } & Field Dependent & 35 & 48.6 & 48.6 & 48.6 \\
\hline & Field Independent & 37 & 51.4 & 51.4 & 100.0 \\
\hline & Total & 72 & 100.0 & 100.0 & \\
\hline
\end{tabular}

Table 4 indicates the number of participants belonging to impulsive andreflectivegroups.

Table 4. Descriptive Statistics-Impulsive/Reflective

\begin{tabular}{|cc|c|c|c|c|}
\hline & & Frequency & Percent & Valid Percent & $\begin{array}{c}\text { Cumulative } \\
\text { Percent }\end{array}$ \\
\hline Valid & Reflective & 47 & 65.3 & 65.3 & 65.3 \\
& Impulsive & 25 & 34.7 & 34.7 & 100.0 \\
& Total & 72 & 100.0 & 100.0 & \\
\hline
\end{tabular}

Table 5 shows that, out of 47 reflective participants, 15 belonged to the field dependent group and the remaining 32 belonged with the field independent group. Moreover, out of 25 impulsive participants, 20 were field dependent and 5 were field independent.

Table 5. Field Dependency Level * Impulsive/Reflective Cross tabulation

\begin{tabular}{|cc|c|c|c|}
\hline & & \multicolumn{2}{|c|}{ Impulsive/Reflective } & \multirow{2}{*}{ Total } \\
\cline { 3 - 5 } & & Reflective & Impulsive & 35 \\
\multirow{2}{*}{$\begin{array}{c}\text { Field Dependency } \\
\text { Level }\end{array}$} & Field Dependent & 15 & 20 & 37 \\
& $\begin{array}{c}\text { Field } \\
\text { Independent }\end{array}$ & 32 & 5 & 72 \\
\hline
\end{tabular}

\section{Statistical Analysis of the Research Questions}

To answer the first question of this study and find out whether there exists a significant relationship between field dependence/independence and cloze test performance, a Pearson Product Moment Correlation was launched. As indicated in Table 6, since Sig. (2-tailed) is not less than the 
alpha level of .05, it is concluded that there is nota significant relationship between EFL learners' field dependence/independence and their scores on cloze test.

Table 6. Correlations

\begin{tabular}{|c|c|c|c|}
\hline & & $\begin{array}{c}\text { Field } \\
\text { Dependence/Independence }\end{array}$ & Cloze Test \\
\hline \multirow{3}{*}{$\begin{array}{l}\text { Field Dependence/ } \\
\text { Independence }\end{array}$} & Pearson Correlation & 1 & .095 \\
\hline & Sig. (2-tailed) & & .425 \\
\hline & $\mathbf{N}$ & 72 & 72 \\
\hline \multirow[t]{3}{*}{ Cloze Test } & Pearson Correlation & .095 & 1 \\
\hline & Sig. (2-tailed) & .425 & \\
\hline & $\mathbf{N}$ & 72 & 72 \\
\hline
\end{tabular}

To find out whether there exists a significant relationship between impulsivity/reflectivity and cloze test performance, the second research question, a Pearson Product MomentCorrelation analysis was conducted. As indicated in Table 7, since $p$-value, or Sig. (2-tailed), was not less than the alpha level of .05, it was concluded that there is not a significant relationship between EFL learners' impulsivity/reflectivity and their cloze test performance.

Table 7.Correlations

\begin{tabular}{|cc|c|c|}
\hline & & Impulsivity/Reflectivity & Cloze Test \\
\hline Impulsivity/Reflectivity & Pearson Correlation & 1 & -.213 \\
& Sig. (2-tailed) & & .072 \\
& $\mathrm{~N}$ & 72 & 72 \\
\hline Cloze Test & Pearson Correlation & -.213 & 1 \\
& Sig. (2-tailed) & .072 & \\
& $\mathrm{~N}$ & 72 & 72 \\
\hline
\end{tabular}

In the third research question of this research, the relationship between field dependence/independence and impulsivity/reflectivity was questioned. To obtain the answer a Pearson Correlation was utilized, the result of which is presented in Table 8.

Table 8. Correlations

\begin{tabular}{|c|c|c|c|}
\hline & & $\begin{array}{c}\text { Field } \\
\text { Dependence/Independence }\end{array}$ & Impulsivity/Reflectivity \\
\hline \multirow[t]{3}{*}{$\begin{array}{l}\text { Field Dependence/ } \\
\text { Independence }\end{array}$} & $\begin{array}{c}\text { Pearson } \\
\text { Correlation }\end{array}$ & 1 & $-.309 * *$ \\
\hline & Sig. (2-tailed) & & .012 \\
\hline & $\mathbf{N}$ & 72 & 72 \\
\hline \multirow[t]{3}{*}{ Impulsivity/Reflectivity } & $\begin{array}{c}\text { Pearson } \\
\text { Correlation }\end{array}$ & & 1 \\
\hline & Sig. (2-tailed) & .012 & \\
\hline & $\mathbf{N}$ & 72 & 72 \\
\hline
\end{tabular}


Since $p$-value (.012) is less than .05, there is a negative and moderately

highsignificant relationship between Field Dependence/Independence and Impulsivity/Reflectivity. Since these constructs are polar, considering the information presented in table 5 , it can be asserted that field independent participants were more reflective (32 out of 47), while the majority of field dependents had impulsive tendencies (20 out of 25).

The fourth research question aimed at findingdifferences between males and females regarding their scores on field dependence/independence, impulsivity/reflectivity, and cloze test. To answer this general question, three independent samples t-tests were utilized.

Table 9.T-Test for the three variables in Two Groups of males and females

\begin{tabular}{|c|c|c|c|c|c|c|c|c|c|c|}
\hline \multirow{2}{*}{ Gender } & \multicolumn{3}{|c|}{ Male } & \multicolumn{3}{c|}{ Female } & \multirow{2}{*}{ Df } & \multirow{2}{*}{ Sig. } \\
\cline { 2 - 10 } & $\mathrm{N}$ & Mean & SD & N & Mean & SD & & & \\
\hline $\begin{array}{c}\text { Field } \\
\text { Dependence/Independence }\end{array}$ & 25 & 9.12 & 4.43 & 47 & 9.51 & 4.69 & -.34 & 70 & .73 \\
\hline Impulsivity/Reflexivity & 25 & $\mathbf{8 . 8 8}$ & 3.19 & 47 & 7.06 & 3.26 & 2.26 & 70 & $.02^{* *}$ \\
\hline Cloze Test & 25 & 12.48 & 4.16 & 47 & 13.72 & 4.63 & -1.12 & 70 & .26 \\
\hline
\end{tabular}

According to the results presented in Table 9, there are not any significant differences between male and female EFL learners regarding field dependence/independence and cloze test scores. The reason is that none of the mentioned variables ( 0.73 and 0.26 ) had $p$-values lower than .05 .

Nevertheless, when it comes to impulsivity/reflectivity, since $p=.02$ is smaller than $\alpha=0.05$, there is a significant difference between males and females regarding their impulsivity/reflectivity (Table 9).Comparing the means obtained from males $(M=8.88)$ and female participants $(M=7.06)$ and considering the fact that higher scores indicate impulsiveness, it can be concluded that male students in this study turned out to be more impulsive than female students.

\section{Discussion}

Considering the relationship between field dependence/independence and impulsivity/reflectivity, it was found that field independent students were more reflective and filed dependent students were more impulsive.This is in line with findings of Campbell and Douglas (1972) and Rozencwajg and Corroyer (2005). Findings also confirmed the studies of (Feij, 1976;Loo \& Townsend 1977; Massari,1975), indicating a significant positive relationship between field independent learners and their reflectiveness. Results also confirm Keogh and Donlon (1972) and Gargiulo (1982) findings that indicate significant positive correlation between field dependency and impulsivity and also between field independency and reflectivity. However findings of this study were in conflict with Jamieson's (1992). 
In this study, field dependence/independence did not seem to be affected by gender. This confirms findings of Morf and Howitt (1970) and Khan (1987), and is in contrast with findings of Lotwick et. al. (1981) and Bosacki et al. (1997).

The statistically insignificant relationship between learners' cloze test performance and other variables revealed that at least for this sample of Iranian EFL students the cognitive styles and gender may not be a factor in interpreting the learners' cloze test performance. However, a positive relationship was found between field independency and cloze test performance, but this relationship was not significant at all.

Therefore, the findings of this study concerning the relationship between filed dependence/independence and cloze test performance are in contrast with the studies ofBlanton (2004) who investigated the relationship between field dependence/independence and multiple choice items, and Hansen and Stansfield (2006)who studied the relationship between the two cognitive styles and linguistic and integrative competence.However the findings of this study are in line with the findings ofWells (2000), Shih and Gamon (2001)who studied online course achievements and the two cognitive styles, and Soozandefar and Souzandehfar (2011) who studied the relationship between field dependence/independence and speaking performance.

This study found no relationship between impulsivity/reflectivity and cloze test performance. However, like field dependence/independence, a non-significant positive relationship was found. The finding of this study related to impulsivity/reflectivity and cloze test performance is in line with findings of Jamieson (1992) who reported that impulsivity and reflectivity were neither positively nor negatively related to language proficiency, but it is in contrast with findings of Bazargani and Noroozi (2013).

Considering gender differences affecting other variables, the only variable that seemed to be affected by gender was impulsivity/reflectivity. It was found that females were more reflective than males who were more impulsive. This confirmsfindings of Lewis, Rausch, Goldberg, and Dodd (1968), and Lewis (1971). However, it is in contrast with Messer's (1976) findings.

\section{Conclusion}

According to the findings of this study, the cognitive styles, field dependence/independence and impulsivity/ reflectivity, were one of the two pairs of variables which had a significant relationship with each other. According to Huteau (1987, as cited in Rozencwajg \& Corroyer, 2005) the pair of variables have three components in common:attention allocation behavior, a general intelligence factor, and motivational processes. The other 
significantly related pair of variableswas impulsivity/reflectivity and gender. This might be because males tend to be more risk taker than females.

Considering the relationship between field dependence/independence and students' cloze test performance, most of the studies found that field independence has a positive influence on different aspects of learning and achievement. Although in this study this relationship was not found to be significant,a positive relationship existed.

The relationship between impulsivity/reflectivity and students’ cloze test performance, although positive, was also found to be insignificant.Considering the positive correlation, the findings of this study can be useful for English teachers involved in language testing.The teachers' judgment about students' scores on different types of tests including cloze test or multiple choice items should not be merely attributed to their language ability, but factors such as the reflectivity/ impulsivity and field dependence/independence cognitive styles of test takers shouldalso be taken into consideration.

\section{References:}

Bazargani, D. T., \& V. Noroozi (2013). Impulsivity-reflectivity, gender, and performance on multiple choice items. International Journal of Language Learning and Applied Linguistics World, 4(2), 194-208.Retrieved from: http://www.ijllalw.org/Past-Issues.html

Blakely, P. N., \& Tomlin, A. H. (2008).Adult education: issues and developments.New York: Nova Science Publishers, Inc.

Bosacki, S., \& Innerd, W., \& Towson, S. (1997).Field independencedependence and self-esteem in preadolescents: does gender make a difference? Journal of Youth and Adolescence, 26(6), 691-703.

Brown, H. D. (Eds.). (2007). Principles of language learning and teaching (5 $5^{\text {th }}$ ed.).New York, US: Pearson Education, Inc.

Campbell, S. B., \& Douglas, V. I. (1972). Cognitive styles and responses to the threat of frustration. Canadian Journal of Behavioral Science, 4(1), 3042. DOI: $10.1037 / \mathrm{h} 0082287$

Chapelle, C., \& Roberts, C. (1986).Ambiguity tolerance and field independence as predictors of proficiency in English as a second language.Language Learning, 36 (1), 27-45.

Eysenck, S. B. G., \& Eysenck, H. J. (1978). Impulsiveness and venturesomeness: their position in a dimensional system of personality description. Psychological Reports, 43(3), 1247-1255.DOI: 10.2466/PR0.43.7.1247-1255

Farhadi, H., Jafarpur, A., \& Birjandi, P. (2012).Testing language skills from theory to practice. Tehran: The editorial staff of SAMT. 
Feij, J. A. (1976). Field independence, impulsiveness, high school training, and academic achievement. Journal of Educational Psychology, 68(6), 793799. DOI: $10.1037 / 0022-0663.68 .6 .793$

Gargiulo, R. M. (1982). Reflection/impulsivity and field dependence/independence in retarded and non retarded children of equal mental age. Bulletin of the Psychometric Society, 19(2), 74-77.

Hansen, J., \& Stansfield, C. (1981).The relationship of field dependentindependent cognitive styles to foreign language achievement. Language Learning, 31(2), 349-367. DOI: 10.1111/j.1467-1770.1981.tb01389.x

Jamieson, J. (1992). The cognitive styles of reflection/impulsivity and field independence and ESL success. Modern Language Journal, 76, 491-501.

Kagan, J., Rosman, B. L., Day, D., Albert, J.,\& Phillips, W. (1964).Information processing in the child: Significance of analytic and reflective attitudes. Psychological Monographs: General and Applied, 78(1), 1-37. DOI: 10.1037/h0093830

Keog, B. K.,\& Donlon, G. M. (1972). Field Dependence, Impulsivity, and Learning Disabilities.Journal of Learning Disabilities, 5(6), 331-336.

DOI: 10.1177/002221947200500603

Khan, S. (1987). Sex differences in field dependence and socialization in a group of Pakistani children. Pakistan Journal of Psychological Research, 2(1-2), 3-16.

Lewis, M. (1971). Sex differences in cognitive style: A rejoinder. Perceptual and Motor Skills,33(3), 1006. DOI:10.2466/pms.1971.33.3.1006

Lewis, M., Rausch, M., Goldberg, S., \& Dodd, C. (1968). Error, response time, and IQ: Sex differences in cognitive style of preschool children. Perceptual Motor Skills, 26(2), 563-568. DOI: 10.2466/pms.1968.26.2.563

Loo, R., \& Townsend, P. J. (1977). Components Underlying the Relation between Field Dependence and Extroversion. Perceptual and Motor Skills, 45(2), 528-530.

Lotwick, G. H., Simon, A., \& Ward, L. O. (1981). Field dependence/independence and its relation to sex of polytechnic students. Perceptual and Motor Skills, 53(1), 271-272. DOI: 10.2466/pms.1981.53.1.271

Maghsudi, M. (2007). The interaction between field dependent/independent learning styles and learners' linguality in third language acquisition. Languagein India, 7, 1-16.

Massari, D. J. (1975). The relation of reflection-impulsivity to filed dependence-independence and internal-external control in disadvantaged preschool children.Journal of Genetic Psychology, 126, 61-67.

Messer, S. B. (1976). Reflection-impulsivity: A review. Psychological Bulletin, 83(6), 1026-1052. DOI: 10.1037/00332909.83.6.1026 
Morf, M. E., \& Howitt, R. (1970). Rod-and-frame test performance as a function of momentary arousal. Perceptual and Motor Skills, 31, 307-308. Oller, J. W.,\& Perkins, K. (1980).Research in language testing. Rowley, Mass.: NewburyHouse.

Onyekuru, B. U. (2015). Field dependence-field independence cognitive style, gender, career choice and academic achievement of secondary school students in Emohua local government area of Rivers State. Journal of Education and Practice, 6(10), 76-85.

Rezai, M. J., \& Noori, M. (2013). On the effects of gender, age, status, years of EFL learning, and proficiency level on the fieldindependency/dependency of EFL learners and instructors.Iranian EFL Journal, 9(3), 409-428.

Richards, J. C., \& Schmidt, R. (Eds.).(2002). Longman dictionary of language teachingand applied linguistics $\left(3^{\text {rd }}\right.$ ed.).London: Pearson Education Limited.

Riding, R., \& Sadler-Smith, E. (1992). Type of instructional material, cognitive style and learning performance. Educational Studies, 3(18), 323340.

Rozencwajg, P., \& Corroyer, D. (2005). Cognitive processes in the reflective-impulsive cognitive style. The Journal of Genetic Psychology, 166(4), 451-463.

Ryan, K., \& Bachman, L. (1992). Differential item functioning on two tests of EFL proficiency. Language Testing, 9(1), 12-29.

Shih, C. C., \& Gamon, J. (2001).Web-based learning: Relationships among student motivation, attitude, learning styles, and achievement. Journal of Agricultural Education, 42(4), 12-20.

Soozandehfar, S. M., \& Souzandehfar, M. (2011).The effects of fielddependent/field-independent cognitive styles and gender on second language speaking performance. California Linguistic Notes, 36(2).

Wells, J. G. (2000). Effects of an on-line computer-mediated communication course, prior computer experience and internet knowledge and learning styles on students' internet attitudes. Journal of Industrial Teacher Education, 37(3), 22-53.

Witkin, H. A. (1967). A cognitive-style approach to cross-cultural research. International Journal of Psychology, 2(4), 233-250.

Witkin, H. A., Oltman, P. K., Raskin, E., \& Karp, S. A. (1971). Group embedded figures test manual. Palo Alto, CA: Consulting Psychology Press. 